\title{
Wenn man für das Leben anderer verantwortlich ist ...
}

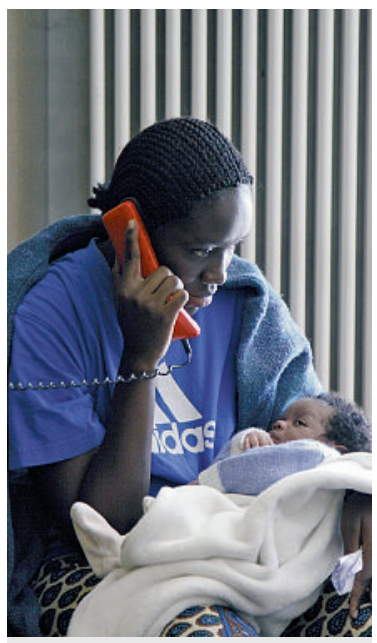

Szene aus dem Film «La Forteresse» von Fernand Melgar.
«La Forteresse» des Lausanner Regisseurs Fernand Melgar muss man gesehen haben. Dieser Film des Sohns spanischer Einwanderer wurde anlässlich des Festivals von Locarno mit dem Goldenen Leoparden ausgezeichnet. Er beschreibt den Alltag in einem Empfangszentrum für Asylbewerber im waadtländischen Vallorbe im Winter 2007-2008. In den 90 Minuten wird der Zuschauer in die Situation aller Akteure versetzt: in die des Asylsuchenden, des Beamten, der die Begründungen anhört und einschätzt, des Sicherheitsund des Verwaltungsbeamten, in die der Seelsorger ... Es ist eine beeindruckende Dokumentation, die nach Neutralität sucht und den Alltag filmt, ohne Urteil und ohne Schuldzuweisungen. Es sind berührende Schicksale von Gestrandeten, die an unsere «Ufer» gespült werden. Wie ein Kommentator sagt, nehmen für den Betrachter die existentiellen «Herausforderungen physische Gestalt an in diesem Mikrokosmos, in dem Welten aufeinanderprallen. Auf der einen Seite die Besitzenden, die nicht das ganze Elend der Welt aufnehmen können, und auf der anderen Seite die Verdammten dieser Erde».

Man wird an den Satz eines Bundesrates im Zweiten Weltkrieg erinnert: «Das Boot ist voll.» Es stimmt, es gibt Grenzen, aber wer weiss, wo sie festzulegen sind? Dazu eine Geschichte: Ich erinnere mich, welche Bedenken mich quälten, als ich vor rund zwanzig Jahren den Vorsitz der Zulassungskommission einer Schule für Physiotherapie innehatte und wir nur einen von zehn Bewerbern aufnehmen konnten. Am Abend der Auswahl grübelte ich darüber nach, was nun aus all den Übriggebliebenen werden würde, denen wir auf der Grundlage unzureichender Kriterien den Weg zum Physiotherapeuten versperrt hatten ... Doch welche Aufgabe haben erst die Interviewer zu erfüllen, die jeden Asylsuchenden anhören und nach bestem Wissen und Gewissen einen Bericht erstellen müssen? Sie haben die Verantwortung, sich im Verlauf weniger Interviews über Qualität und Quantität der Gründe, die einen Menschen oder eine Familie an unsere Grenze geführt haben, ein Urteil zu bilden. «Es gibt Menschen, an die ich mich mein Leben lang erinnern werde. Gespräche, nach denen ich mich vollkommen erschöpft und leer gefühlt habe», sagt ein Interviewer. Man kann diesen Beamten wünschen, dass sie diese Situationen, in denen es kein eindeutiges Urteil gibt, eine ambivalente Entscheidung gefällt werden muss, die aber letztendlich zum «Nein» führt, irgendwie vergessen und zum Alltag übergehen können. Ich war Kantonsarzt, und meine Arbeit war oft nicht einfach. Häufig stand ich vor schwierigen Situationen. Ich gebe aber zu, dass ich meine frühere Verantwortung im Vergleich zu der unserer Mitbürger, die über das Schicksal von Asylsuchenden entscheiden müssen, vorziehe.
Auch die Ärzte tragen in ihrer täglichen Praxis hohe Verantwortung und es wird Missbrauch unterstellt - man denke nur an die IV. Zwar ist die Tragweite nicht dieselbe, aber auch sie müssen über den weiteren Lebensverlauf des Menschen entscheiden, der ihnen gegenübersitzt. In gewisser Weise ist es auch hier das Boot, das mehr oder weniger voll ist, der Topf der Bundeskasse. Und es muss entschieden werden, ob Menschen mit Behinderungen oder starken Beeinträchtigungen oder Menschen, die von Suchtmitteln abhängig sind, in das Boot aufgenommen werden oder nicht. Selbst wenn sie es zuweilen gerne tun würden, steht sowohl aus berufsethischen als auch staatsbürgerlichen Gründen ausser Frage, dass Ärzte sich nicht der Mechanismen der Sozialversicherung bedienen dürfen, um nicht gerechtfertigte Hilfen zu bewilligen. Ihre Stellungnahme darf weder ein Urteil über den (zu begutachtenden) Patienten, noch über die Gesellschaft und die Regeln, die sie sich auferlegt hat, sein. Jedenfalls haben ihre Berichte, wie die der Interviewer im Asylverfahren, schwere Konsequenzen für die Menschen, die im Leben Schiffbruch erlitten haben und bei denen oft schwer zu sagen ist, in welchem Mass sie selbst verantwortlich sind.

Denn die Wahrheit - oder auch die Lösung der Probleme - liegt niemals ausschliesslich auf der einen oder der anderen Seite. Dass es Missbrauch gibt, wird niemand bestreiten. Unsere Welt ist nicht vollkommen. Jeder von uns wird irgendwann einmal versuchen, aus einer Sache, und sei es nur einen kleinen, Profit zu ziehen. Doch wäre es interessant, wenn jene, die unsere sozialen Systeme öffentlich anprangern, einmal einen Tag in der Praxis eines Hausarztes oder eines IV-Gutachters verbringen würden und sich die ausweglosen Schicksale ansehen müssten! Und ebenso interessant wäre es, «La Forteresse» einmal auf den Versammlungen der nationalistischen Kräfte zu zeigen, die bei jeder Gelegenheit behaupten, wir seien eine von Betrügern und Profiteuren durchsetzte Gesellschaft?

Das Wesentliche ist zu vermeiden, dass es zu Ungleichbehandlung oder, schlimmer noch, zu schreiender Ungerechtigkeit kommt. Angesichts dieser Geschichten Einzelner oder ganzer Familien (und hier sei nochmals betont, dass «La Forteresse» nicht für bestimmte politische Ansichten wirbt, sondern ein Dokumentarfilm ist), beschäftigt einen danach die Frage, was aus all diesen Menschen wird, die wieder ihrem Schicksal überlassen werden («Sie haben vierundzwanzig Stunden, um das Land zu verlassen»).

Dr. med. Jean Martin, Mitglied der Redaktion und der Nationalen Ethikkommission 